\title{
Impact of Depression on Weight Variation after Bariatric Surgery: A Three-Year Observational Study
}

\author{
Jorge Pedro $^{a-c}$ João Sérgio Neves ${ }^{a-c}$ Maria João Ferreira ${ }^{a-c}$ \\ Vanessa Guerreiro ${ }^{a-c}$ Daniela Salazar ${ }^{a-c}$ Sara Vianad \\ Fernando Mendonça ${ }^{a-c}$ Maria Manuel Silva ${ }^{a-c}$ Isabel Brandão ${ }^{f}$ \\ Sandra Beloa, e Paula Freitas ${ }^{a-c, e}$ Ana Varela ${ }^{a-c, e}$ Davide Carvalho ${ }^{a-c}$ \\ AMTCO Group ${ }^{\mathrm{e}}$ \\ a Department of Endocrinology, Diabetes and Metabolism, Centro Hospitalar Universitário \\ de São João, Porto, Portugal; ${ }^{b}$ Faculty of Medicine, University of Porto, Porto, Portugal; \\ 'Institute for Research and Innovation in Health, University of Porto, Porto, Portugal; \\ dDepartment of Internal Medicine, Unidade Local de Saúde do Norte Alentejano, Évora, \\ Portugal; e Multidisciplinary Group for Surgical Management of Obesity, Centro Hospitalar \\ Universitário de São João, Porto, Portugal; ${ }^{\mathrm{f}}$ Department of Psychiatry and Mental Health, \\ Centro Hospitalar Universitário de São João, Porto, Portugal
}

\section{Keywords}

Depression · Bariatric surgery $\cdot$ Weight loss $\cdot$ BMI $\cdot$ Psychiatric aspects

\begin{abstract}
Introduction: The association between obesity and depression has been repeatedly established. However, little is known about the impact that the diagnosis of depression before bariatric surgery (DDBS) may have on weight loss. Objective: To evaluate the impact of DDBS on weight outcomes. Methods: Retrospective study of patients submitted to BS. Patients with no weight, no current medication data, or those submitted to revision surgery were excluded. Patients were considered to have DDBS based on taking antidepressants prior to BS or if there was a medical history of past or current depression. Patients with and without a depression history were compared using independent $t$ test. A multivariate logistic regression model was created to evaluate predictors of weight variation (variables included: age, sex, and type of surgery). Results: A total of 616 patients did not have a history of depression and 230 had DDBS. There was a statistically significant difference in the BMI variation between groups. On average, individuals with DDBS lost $1.4 \mathrm{~kg} / \mathrm{m}^{2}$ less than those without DDBS. In the multivariate analysis, the group with DDBS, compared with the group without DDBS, presented on
\end{abstract}


Pedro et al.: Diagnosis of Depression, Bariatric Surgery and Weight Outcomes

average less $-0.9 \mathrm{~kg} / \mathrm{m}^{2}(95 \% \mathrm{Cl}-1.7$ to $-0.2, p=0.018) \mathrm{BMI}$ variation. Conclusion: DDBS is a predictor of lower weight loss after the surgical procedure. Even after adjusting for confounding variables such as age, sex, and BS type, this effect remains. ( 2020 The Author(s)

Published by S. Karger AG, Basel

\section{Introduction}

Obesity is a complex and very prevalent chronic disease that represents a major public health problem [1]. There are several modalities for the treatment of obesity and its comorbidities: lifestyle modification (i.e., increased physical activity or nutritional program with caloric restriction), psychosocial intervention, drugs, and bariatric surgery (BS). Conservative therapies are frequently unsuccessful in achieving long-term weight reduction in morbid obesity. Contrariwise, there is robust evidence that BS is a safe procedure, with excellent results in the reduction of weight, obesity-related comorbidities, and even mortality $[2,3]$.

Like obesity, depression is a common public health problem. Both diseases are associated with high morbidity and mortality and represent a major source of expenditure for the health system and families affected by these conditions. Several epidemiological studies and metaanalyses have shown the coexistence between obesity and depression, thus showing that it is imperative to approach these entities holistically $[4,5]$.

Unlike nonsurgical treatments of obesity, whose risks are low and whose process can be stopped at any time, bariatric surgery has inherent risks and implies that the patient adopts highly restrictive and long-term behavioral changes afterwards. Therefore, these patients are normally requested to complete an exhaustive evaluation, including psychological assessment, to determine their appropriateness for surgery. Although psychological evaluation is mandatory for most surgery programs, there are no clear guidelines about what that assessment must involve [6]. In addition, after the procedure, psychological counseling is often neglected, which may have an impact on weight variation and in the achievement of long-term goals in this group of patients [7].

As is well known, weight regain after BS can occur and therefore all efforts must be made in order to prevent such occurrence. Several factors can explain this, each of which has high interindividual variability $[7,8]$.

In most current literature, improved long-term depression outcomes among BS patients have been shown, although some studies have not demonstrated improvement and others have revealed worsening [9-11]. However, little is known about the impact that the diagnosis of depression before bariatric surgery (DDBS) may have on weight loss.

With this work, we aimed to evaluate the impact of DDBS on weight loss 3 years after BS.

\section{Material and Methods}

We retrospectively analyzed all patients submitted to BS - Roux-en-Y gastric bypass (RYGB), adjustable gastric banding (AGB), or sleeve gastrectomy (SG) - between January 2009 and June 2017 in our center, a tertiary care academic hospital.

In our institution, a multidisciplinary team that includes endocrinologists, bariatric surgeons, nutritionists, psychiatrists, and psychologists evaluate all patients considered for BS. To be a suitable candidate, patients must be between 18 and 65 years old, have a BMI $\geq 40 \mathrm{~kg} / \mathrm{m}^{2}$ (or $\geq 35 \mathrm{~kg} / \mathrm{m}^{2}$ and at least one obesity-related comorbidity) and be compliant with a dietary plan for at least 12 months. After surgery, all patients have scheduled medical 
Pedro et al.: Diagnosis of Depression, Bariatric Surgery and Weight Outcomes

Table 1. Comparison of clinical characteristics between patients with and without DDBS

\begin{tabular}{|c|c|c|c|c|}
\hline Baseline features & $\begin{array}{l}\text { All patients } \\
(n=846)\end{array}$ & $\begin{array}{l}\text { DDBS } \\
(n=230)\end{array}$ & $\begin{array}{l}\text { Without DDBS } \\
(n=616)\end{array}$ & $p$ \\
\hline Age, years & $43.1 \pm 10.5$ & $45.6 \pm 9.5$ & $42.2 \pm 10.7$ & $<0.001$ \\
\hline Female sex & $740(87.5)$ & 209 (90.9) & $531(86.2)$ & 0.068 \\
\hline AGB & $160(18.9)$ & $50(21.7)$ & $110(17.9)$ & \\
\hline SG & $194(22.9)$ & $53(23.0)$ & 141 (22.9) & \\
\hline RYBG & $492(58.2)$ & $127(55.2)$ & 365 (59.3) & 0.406 \\
\hline Diabetes & & & & 0.653 \\
\hline Yes & $120(15.0)$ & $34(16.0)$ & $86(14.7)$ & \\
\hline No & $679(85.0)$ & $179(84.0)$ & $500(85.3)$ & \\
\hline Hypertension & & & & 0.152 \\
\hline Yes & $179(24.3)$ & $41(20.6)$ & 138 (25.7) & \\
\hline No & $557(75.7)$ & $158(79.4)$ & $399(74.3)$ & \\
\hline Dyslipidemia & & & & 0.423 \\
\hline Yes & $316(42.8)$ & $89(45.2)$ & 227 (41.9) & \\
\hline No & $423(57.2)$ & 108 (54.8) & 315 (58.1) & \\
\hline Initial weight & $114.9 \pm 17.4$ & $111.3 \pm 17.1$ & $116.2 \pm 17.4$ & $<0.001$ \\
\hline Weight 3 years after BS & $81.9 \pm 16.0$ & $81.4 \pm 15.9$ & $82.1 \pm 16.0$ & 0.576 \\
\hline Weight variation & $-32.9 \pm 15.5$ & $-29.9 \pm 15.3$ & $-34.1 \pm 15.4$ & $<0.001$ \\
\hline Initial BMI & $44.0 \pm 5.4$ & $43.2 \pm 5.1$ & $44.3 \pm 5.4$ & 0.008 \\
\hline BMI 3 years after BS & $31.4 \pm 5.6$ & $31.7 \pm 5.7$ & $31.3 \pm 5.5$ & 0.469 \\
\hline BMI variation & $12.6 \pm 5.8$ & $11.6 \pm 5.8$ & $13.0 \pm 5.7$ & 0.001 \\
\hline
\end{tabular}

Values are means \pm SD or $n(\%)$. DDBS, diagnosis of depression before bariatric surgery; AGB, adjustable gastric banding; SG, sleeve gastrectomy; RYBG, Roux-en-Y gastric bypass; BMI, body mass index.

visits at 1, 3, and 6 months, and then every 6 months up to 3 years and yearly thereafter up to 6 years. Before each appointment, a fasting venous blood sample was collected to all patients.

All procedures were performed according to standard techniques. Band calibrations were performed at discretion of the attending surgeon. Patients with no weight or no current medication data or those submitted to revision surgery were excluded. Patients were considered to have DDBS based on taking antidepressants prior to BS or if there was a medical history of past or current history of depression. That information was obtained by consulting the patient's clinical records. Diabetes was defined as a fasting blood glucose $\geq 126 \mathrm{mg} / \mathrm{dL}$ and glycosylated hemoglobin $\geq 6.5 \%$ or the use of drugs to treat the disease. Hypertension was defined as a systolic blood pressure $\geq 140 \mathrm{~mm} \mathrm{Hg}$ or a diastolic blood pressure $\geq 90 \mathrm{~mm} \mathrm{Hg}$ or the use of drugs to treat the disease. Dyslipidemia was defined as LDL cholesterol $\geq 130 \mathrm{mg} / \mathrm{dL}$ or triglycerides $\geq 150 \mathrm{mg} / \mathrm{dL}$ or the use of drugs to treat the condition. Weight variation (kg) was defined as "weight 3 years after BS - initial weight." BMI was defined as weight $(\mathrm{kg}) /$ height $^{2}\left(\mathrm{~m}^{2}\right)$. BMI variation was calculated as "initial BMI - BMI 3 years after BS."

In the statistical analysis, categorical variables are presented as counts and proportions. Continuous variables are presented as mean (standard deviation) if normally distributed or median (interquartile range) if nonnormally distributed. Baseline characteristics, 3 years post-BS, and its variation, were compared between patients with DDBS and those without DDBS. For comparison, $\chi^{2}$ and Fisher's exact tests were used for categorical variables, a Student $t$ test for normally distributed continuous variables, and a Mann-Whitney U test for skewed continuous variables. We used unadjusted and adjusted logistic regression models to 
Pedro et al.: Diagnosis of Depression, Bariatric Surgery and Weight Outcomes

Table 2. Multivariate analysis of weight variation according to sex, age, and BS type

\begin{tabular}{lccc}
\hline & Adjusted $\beta$ & $95 \%$ CI & $p$ \\
\hline $\begin{array}{l}\text { DDBS } \\
\text { Yes }\end{array}$ & 2.3 & 0.3 to 4.3 & 0.026 \\
$\quad$ No & - & - \\
Sex & & \\
$\quad$ Female & 4.3 & 1.7 to 7 & 0.001 \\
$\quad$ Male & & & \\
Age, years & 0.3 & 0.2 to 0.4 & $<0.001$ \\
$\begin{array}{l}\text { BS type } \\
\quad \text { GB }\end{array}$ & 19.6 & 17.2 to 21.9 & $<0.001$ \\
$\quad$ SG & 5.1 & 2 to 7.3 & $<0.001$ \\
$\quad$ RYBG & - & - & - \\
\hline
\end{tabular}

DDBS, diagnosis of depression before bariatric surgery; BS, bariatric surgery; AGB, adjustable gastric banding; SG, sleeve gastrectomy; RYBG, Roux-en-Y gastric bypass.
Table 3. Multivariate analysis of BMI variation according to sex, age, and BS type

\begin{tabular}{llll}
\hline & Adjusted $\beta$ & $95 \%$ CI & $p$ \\
\hline $\begin{array}{l}\text { DDBS } \\
\text { Yes }\end{array}$ & -0.9 & -1.7 to -0.2 & 0.018 \\
$\quad$ No & - & - \\
Sex & & \\
$\quad$ Female & 0.6 & -0.5 to 1.6 & 0.273 \\
$\quad$ Male & & & \\
$\begin{array}{l}\text { Age, years } \\
\text { BS type }\end{array}$ & -0.1 & -0.1 to -0.04 & $<0.001$ \\
$\quad$ GB & & & \\
SG & -7.4 & -8.3 to -6.5 & $<0.001$ \\
RYBG & -2.1 & -2.9 to -1.3 & $<0.001$ \\
\hline
\end{tabular}

DDBS, diagnosis of depression before bariatric surgery; BS, bariatric surgery; AGB, adjustable gastric banding; SG, sleeve gastrectomy; RYBG, Roux-en-Y gastric bypass.

study if DDBS was a predictor of weight loss variation. The adjusted model included age, sex, and BS type. The $p$ value considered for statistical significance was 0.05. Data was stored and analyzed using SPSS software (IBM Corp., Armonk, NY, USA, version 23.0).

\section{Results}

In the study period, 1,481 patients were submitted to BS in our institution. From these, 635 were excluded due to the presence of exclusion criteria.

We studied 846 patients (Table 1) of which 230 (27.2\%) had DDBS. Most of the patients were women $(n=740,87.5 \%)$, and the mean age was 43 years. The group of patients with DDBS (mean age 45.6 years) was statistically older $(p<0.001$ ) than those without DDBS (mean age 42.2 years). Regarding the type of BS and the presence of comorbidities (diabetes, hypertension, or dyslipidemia), there was no statistically significant difference between the groups. 
The mean initial weight was $114.9 \mathrm{~kg}$, and there were statistically significant $(p<0.001)$ differences between the two groups: patients with DDBS had a mean weight of $111.3 \mathrm{~kg}$ and those without DDBS had a mean weight of $116.2 \mathrm{~kg}$. Taking into account the weight variation, patients with DDBS lost on average $4.1 \mathrm{~kg}$ less than individuals without DDBS and that difference was statistically significant.

In the multivariate analysis (Table 2), there was statistically significant difference between the two groups in the weight variation after adjusting for age, sex, and BS type. The group with DDBS, compared with the group without DDBS, presented on average less $2.3 \mathrm{~kg}$ (95\% CI $0.3-4.3, p=0.026)$ of weight variation, after accounting for the confounding variables.

Taking into account the BMI variation, there was also a statistically significant difference between the two groups. The BMI variation of the group with DDBS was lower than the group without DDBS. On average, individuals with DDBS lost $1.4 \mathrm{~kg} / \mathrm{m}^{2}$ less than those without DDBS.

In the multivariate analysis (Table 3), there was a statistically significant difference between the two groups in the BMI variation after adjusting for age, sex, and BS type. The group with DDBS, compared with the group without DDBS, presented on average $-0.9 \mathrm{~kg} / \mathrm{m}^{2}$ ( $95 \%$ CI -1.7 to $-0.2, p=0.018$ ) less BMI variation, after accounting for the confounding variables.

\section{Discussion}

This study aimed to evaluate the impact of DDBS on weight loss 3 years after BS. We found that patients with DDBS lost on average $4.1 \mathrm{~kg}$ less of absolute weight than those without DDBS and the BMI variation was also $1.4 \mathrm{~kg} / \mathrm{m}^{2}$ less than those without DDBS. It is known, however, that there are some variables that may interfere with the outcomes of weight variation after BS [12-14]. After adjustment for sex, age, and BS type, this effect was maintained. To the best of our knowledge, this is the first study to address the effect of DDBS on weight-related outcomes of BS.

BS is just the beginning of a process that will accompany the patient for the rest of his or her life [3]. Initially, the vast majority of patients will lose weight but later, usually between 18 and 24 months, this weight loss quantitatively decreases and patients may even regain it $[15,16]$. It is therefore crucial that a multidisciplinary team follows the patient for years after BS in order to optimize the outcomes of the procedure. There are several factors that could explain this: metabolic and endocrine factors, failure of the surgical procedure, failure to comply with the food plan, psychiatric problems, or physical inactivity. The preponderance of each of these factors for this to occur is still not well defined and it varies for each individual [8], thus they should be actively sought by the clinician in order to minimize them. It is known that the diagnosis of depression at some point in life puts the patient at risk of recurrence of this disease [17]. Therefore, it must be considered whether these patients should have more extensive psychological follow-up over the years following BS.

Our results firstly found that the vast majority of our study population was female. This trend was maintained when we studied the sex of patients with DDBS. This information is congruent with most studies conducted in populations of patients submitted to BS and in those with a history of depression $[18,19]$. However, when we compared the prevalence of female sex in the population of patients with DDBS with those without this diagnosis, there was no statistically significant difference between the two groups.

Secondly, we found that $27.2 \%$ of our study population had DDBS. As far as we know, our population sample is one of the largest so far studied in this context. This evidence reinforces 
Pedro et al.: Diagnosis of Depression, Bariatric Surgery and Weight Outcomes

the close relationship between obesity and depression and suggests that both pathologies may be dependent on each other [20,21]. Furthermore, this finding is also in line with other studies that had already highlighted the high prevalence of psychiatric symptoms in populations of obese candidates for BS [11, 22, 23].

Regarding the lower weight loss of patients with DDBS, first of all, we have to mention the fact that the group with DDBS presented, on average, less initial weight compared to the group without DDBS. It is known that patients with lower initial weight usually lose less weight than those with higher initial values. Why the group with DDBS of our sample had lower initial weight is largely unknown. We postulate that if the number of patients was greater, this difference could cease to exist. Another legitimate hypothesis would be that some of these patients with DDBS could be taking some antidepressant drugs associated with weight loss (e.g., fluoxetine). Furthermore, we suggest some reasons for the lower weight loss of patients with DDBS: the relationship between depression and binge eating behavior [24] or the lack of motivation that characterizes depression [25]. The signs and symptoms of depression should then be actively sought and in case of doubt or the clear presence of these, patients should be referred to a psychiatrist. Additionally, in most centers, the waiting time for BS is long and suboptimal [26-28]. It is legitimate to question whether these patients, prior to being given as eligible for the surgical procedure, should have clinical stability from the point of view of depression in order to optimize outcomes.

This study has limitations that are worth mentioning. We did not take into account those individuals who started drugs for depression or who were diagnosed with this disease after BS. In addition, we did not take into account the interference of drugs that may influence weight loss or gain.

Despite these limitations, this is, to the best of our knowledge, one of the first works to study the potential effect of depression on weight outcomes in patients undergoing BS. It is essential that other works focus on this problem with the aim of improving the effectiveness of BS.

\section{Conclusion}

DDBS is a predictor of lower weight loss after the surgical procedure. Even after adjusting for confounding variables such as age, sex, and BS type, this effect remains. These results emphasize the importance of the existence of follow-up programs before and after BS in order to optimize outcomes, particularly if there is a personal history of depression.

\section{Acknowledgement}

This work could only be done with the help of former Endocrinology residents, who contributed to collect data from the patients included in this article.

\section{Statement of Ethics}

No ethical approval was obtained because this study did not involve a prospective evaluation, did not involve laboratory animals, and the data collected is confidential. 
Pedro et al.: Diagnosis of Depression, Bariatric Surgery and Weight Outcomes

\section{Disclosure Statement}

The authors have no conflicts of interest to disclose.

\section{Funding Sources}

No funding was received.

\section{Author Contributions}

J. Pedro wrote the article and was involved in patient care. J.S. Neves, M.J. Ferreira, V. Guerreiro, D. Salazar, S. Viana, F. Mendonça, M.M. Silva, AMTCO Group, I. Brandão, S. Belo, P. Freitas, and A. Varela were involved in patient care and helped collecting data. D. Carvalho revised the draft.

\section{References}

1 Frühbeck G, Busetto L, Dicker D, Yumuk V, Goossens GH, Hebebrand J, et al. The ABCD of obesity: an EASO position statement on a diagnostic term with clinical and scientific implications. Obes Facts. 2019;12(2): 131-6.

2 Kissler HJ, Settmacher U. Bariatric surgery to treat obesity [Internet]. Semin Nephrol. 2013 Jan;33(1):75-89.

3 Warholm C, Marie Øien A, Råheim M. The ambivalence of losing weight after bariatric surgery. Int J Qual Stud Health Well-being. 2014 Jan;9(1):22876.

4 Jantaratnotai N, Mosikanon K, Lee Y, McIntyre RS. The interface of depression and obesity [Internet]. Obes Res Clin Pract. 2017 Jan - Feb;11(1):1-10.

5 Tremmel M, Gerdtham UG, Nilsson PM, Saha S. Economic burden of obesity: A systematic literature review. Int J Environ Res Public Health. 2017 Apr;14(4):1-18.

6 Snyder AG. Psychological assessment of the patient undergoing bariatric surgery. Ochsner J. 2009;9(3):144-8.

7 Busetto L, Dicker D, Azran C, Batterham RL, Farpour-Lambert N, Fried M, et al. Obesity Management Task Force of the European Association for the Study of Obesity Released "Practical Recommendations for the PostBariatric Surgery Medical Management”. Obes Surg. 2018 Jul;28(7):2117-21.

8 Kushner RF, Sorensen KW. Prevention of Weight Regain Following Bariatric Surgery. Curr Obes Rep. 2015 Jun; 4(2):198-206.

9 Gill H, Kang S, Lee Y, Rosenblat JD, Brietzke E, Zuckerman H, et al. The long-term effect of bariatric surgery on depression and anxiety [Internet]. J Affect Disord. 2019 Mar;246:886-94.

10 Ribeiro GA, Giapietro HB, Belarmino LB, Salgado-Junior W. Depression, Anxiety, and Binge Eating Before and After Bariatric Surgery: Problems That Remain. Arq Bras Cir Dig. 2018 Jun;31(1):e1356.

11 Booth H, Khan O, Prevost AT, Reddy M, Charlton J, Gulliford MC; Kings Bariatric Surgery Study Group. Impact of bariatric surgery on clinical depression. Interrupted time series study with matched controls [Internet]. J Affect Disord. 2015 Mar;174:644-9.

12 Manning S, Carter NC, Pucci A, Jones A, Elkalaawy M, Cheung WH, et al. Age- and sex-specific effects on weight loss outcomes in a comparison of sleeve gastrectomy and Roux-en-Y gastric bypass: a retrospective cohort study. BMC Obes. 2014 Aug;1(1):12.

13 Praveenraj P, Gomes RM, Kumar S, Perumal S, Senthilnathan P, Parthasarathi R, et al. Comparison of weight loss outcomes 1 year after sleeve gastrectomy and Roux-en-Y gastric bypass in patients aged above 50 years. J Minim Access Surg. 2016 Jul-Sep;12(3):220-5.

14 le Roux CW, Heneghan HM. Bariatric Surgery for Obesity [Internet]. Med Clin North Am. 2018 Jan;102(1): 165-82.

15 Bastos ECL, Barbosa EMWG, Soriano GMS, dos Santos EA, Vasconcelos SML. Determinants of weight regain after bariatric surgery. Arq Bras Cir Dig. 2013;26 Suppl 1(Suplemento 1):26-32.

16 Masood A, Alsheddi L, Alfayadh L, Bukhari B, Elawad R, Alfadda AA. Dietary and Lifestyle Factors Serve as Predictors of Successful Weight Loss Maintenance Postbariatric Surgery. J Obes. 2019 Feb;2019:7295978.

17 Burcusa SL, Iacono WG. Risk for recurrence in depression. Clin Psychol Rev. 2007 Dec;27(8):959-85.

18 Pratt GM, Learn CA, Hughes GD, Clark BL, Warthen M, Pories W. Demographics and outcomes at American Society for Metabolic and Bariatric Surgery Centers of Excellence. Surg Endosc. 2009 Apr;23(4):795-9.

19 Kessler RC, Bromet EJ. The epidemiology of depression across cultures. Annu Rev Public Health. 2013;34: 119-38. 
20 Schachter J, Martel J, Lin CS, Chang CJ, Wu TR, Lu CC, et al. Effects of obesity on depression: A role for inflammation and the gut microbiota [Internet]. Brain Behav Immun. 2018 Mar;69:1-8.

21 Luppino FS, de Witt LM, Bouvy PF, et al. Overweight, obesity, and depression: a systematic review and metaanalysis of longitudinal studies. Arch Gen Psychiatry. 2010 Mar;67(3):220-9.

22 Sarwer DB, Cohn NI, Gibbons LM, Magee L, Crerand CE, Raper SE, et al. Psychiatric diagnoses and psychiatric treatment among bariatric surgery candidates. Obes Surg. 2004 Oct;1148-56.

23 Osterhues A, von Lengerke T, Mall JW, de Zwaan M, Müller A. Health-Related Quality of Life, Anxiety, and Depression in Bariatric Surgery Candidates Compared to Patients from a Psychosomatic Inpatient Hospital. Obes Surg. 2017 Sep;27(9):2378-87.

24 Rosenbaum DL, White KS. The relation of anxiety, depression, and stress to binge eating behavior. J Health Psychol. 2015 Jun;20(6):887-98.

25 Grahek I, Shenhav A, Musslick S, Krebs RM, Koster EH. Motivation and cognitive control in depression [Internet]. Neurosci Biobehav Rev. 2019 Jul;102(March):371-81.

26 Arteaga-González IJ, Martín-Malagón AI, Ruiz de Adana JC, de la Cruz Vigo F, Torres-García AJ, Carrillo-Pallares AC. Bariatric Surgery Waiting Lists in Spain. Obes Surg. 2018 Dec;28(12):3992-6.

27 Alvarez R, Bonham AJ, Buda CM, Carlin AM, Ghaferi AA, Varban OA. Factors Associated With Long Wait Times for Bariatric Surgery. Ann Surg. 2019 Dec;270(6):1103-9.

28 Casimiro Pérez JA, Fernández Quesada C, Del Val Groba Marco M, Arteaga González I, Cruz Benavides F, Ponce J, et al. Obesity Surgery Score (OSS) for Prioritization in the Bariatric Surgery Waiting List: a Need of Public Health Systems and a Literature Review. Obes Surg. 2018 Apr;28(4):1175-84. 